\title{
Airflow limitation or static hyperinflation: which is more closely related to dyspnea with activities of daily living in patients with COPD?
}

\author{
Koichi Nishimura1*, Maya Yasui ${ }^{2}$, Takashi Nishimura ${ }^{2}$ and Toru Oga ${ }^{3}$
}

\begin{abstract}
Background: Dyspnea while performing the activities of daily living has been suggested to be a better measurement than peak dyspnea during exercise. Furthermore, the inspiratory capacity (IC) has been shown to be more closely related to exercise tolerance and dyspnea than the $\mathrm{FEV}_{1}$, because dynamic hyperinflation is the main cause of shortness of breath in patients with COPD. However, breathlessness during exercise is measured in most studies to evaluate this relationship.
\end{abstract}

Purpose: To evaluate the correlation between breathlessness during daily activities and airflow limitation or static hyperinflation in COPD.

Methods: We examined 167 consecutive outpatients with stable COPD. The Baseline Dyspnea Index (BDI) was used to evaluate dyspnea with activities of daily living. The relationship between the BDI score and the clinical measurements of pulmonary function was then investigated.

Results: The Spearman rank correlation coefficients (Rs) between the BDI score and the $F E V_{1}(L), F E V_{1}(\% p r e d)$ and $\mathrm{FEV}_{1} / \mathrm{FVC}$ were $0.60,0.56$ and 0.56 , respectively. On the other hand, the BDI score also correlated with the IC, IC/ predicted total lung capacity (TLC) and IC/TLC (Rs $=0.45,0.46$ and 0.47 , respectively). Although all of the relationships studied were strongly correlated, the correlation coefficients were better between dyspnea and airflow limitation than between dyspnea and static hyperinflation. In stepwise multiple regression analyses, the BDI score was most significantly explained by the $\mathrm{FEV}_{1}\left(\mathrm{R}^{2}=26.2 \%\right)$ and the diffusion capacity for carbon monoxide $\left(R^{2}\right.$ $=14.4 \%$ ) (Cumulative $R^{2}=40.6 \%$ ). Static hyperinflation was not a significant factor for clinical dyspnea on the stepwise multiple regression analysis.

Conclusion: Both static hyperinflation and airflow limitation contributed greatly to dyspnea in COPD patients.

Keywords: Chronic obstructive pulmonary disease, Airflow limitation, Hyperinflation, Dyspnea, Baseline Dyspnea Index

\section{Background}

Dyspnea is multifactorial, but static lung hyperinflation and its increase during exercise (dynamic hyperinflation) is believed to be the most important in subjects with chronic obstructive pulmonary disease (COPD) [1-3]. It has been reported that indices related to hyperinflation, such as the inspiratory capacity (IC), are more closely related to exercise tolerance and dyspnea than the

\footnotetext{
* Correspondence: koichi-nishimura@nifty.com

'Department of Respiratory Medicine, Rakuwakai Otowa Hospital, Kyoto, Japan

Full list of author information is available at the end of the article
}

forced expiratory volume in 1 second $\left(\mathrm{FEV}_{1}\right)$ or forced vital capacity (FVC) [4-8]. The Borg scale is frequently used during exercise as a marker of laboratory dyspnea in physiological investigations to evaluate this relationship. Furthermore, Casanova and colleagues proved that static lung hyperinflation estimated by the inspiratory capacity-to-total lung capacity (IC/TLC) ratio is a predictor of all-cause and respiratory mortality in patients with COPD, independent of the $\mathrm{FEV}_{1}$ [9].

The outcome measurements for dyspnea can be broadly divided into those that assess breathlessness during exercise (laboratory dyspnea), and those that

\section{Biomed Central}


assess overall breathlessness during daily activities (clinical dyspnea). Using factor analysis, Hajiro et al. [10] reported that various clinical dyspnea ratings were virtually identical for evaluating dyspnea in COPD patients. On the other hand, dyspnea at the end of maximal exercise may provide a different type of information regarding dyspnea [10]. It has also been reported that dyspnea during daily activities was more significantly correlated with objective and subjective measurements of COPD than dyspnea at the end of exercise, and that the former was more predictive of mortality [11]. Therefore, dyspnea while performing the activities of daily living is considered to be a better measurement for evaluating the disease severity of COPD than peak dyspnea during exercise.

We hypothesized that static hyperinflation may be more closely related to clinical dyspnea than laboratory dyspnea, since there is a close relationship between the IC and exercise performance and dyspnea in COPD. The purpose of this observational study was to evaluate the correlation between breathlessness during daily activities measured using the Baseline Dyspnea Index (BDI) and airflow limitation or static hyperinflation in COPD.

\section{Methods}

A total of 167 consecutive patients with stable COPD defined as a $\mathrm{FEV}_{1} / \mathrm{FVC}$ of less than 0.7 for all measurements made during the previous 6 months were recruited at the outpatient clinic of the Respiratory division of Kyoto-Katsura Hospital. The entry criteria included: (1) a diagnosis of COPD and an age over 40 years; (2) a self-reported current or former smoker; (3) regular attendance at our clinic for more than 6 months to avoid substantial changes in subjective parameters brought about by new medical interventions; and (4) no changes in the treatment regimen for more than 4 weeks. Patients with any history suggestive of asthma, a never-smoker, an exacerbation of their COPD over the preceding 6 weeks, previous inflammatory changes revealed on chest radiographs that could influence pulmonary function (for example, a previous thoracoplasty or tuberculous sequelae), or any other illnesses, were excluded. All eligible patients underwent the following examinations on the same day. None of the results from the 167 patients in the present study have been published elsewhere. Informed consent was obtained from all participants.

On the evaluation day, the patients completed their pulmonary function tests, arterial blood gas (ABG) analyses, blood investigation, chest X-rays and dyspnea measurements. The patients were requested to stop using tiotropium bromide for 24 hours before, and were also asked to discontinue the use of other inhaled bronchodilators for at least 12 hours before the assessment. According to the method described by the ATS/ ERS Task Force in 2005 [12], three acceptable spirometric flow-volume curves were recorded with the patient sitting using a calibrated 2.0-L syringe before every measurement. The largest $\mathrm{FEV}_{1}$ and the largest FVC among three maneuvers were then analyzed. The predicted values for the $\mathrm{FEV}_{1}$ and vital capacity (VC) were calculated according to the proposal from the Japan Society of Chest Diseases [13]. The residual volume (RV) was measured by the closed-circuit helium method, and the diffusion capacity for carbon monoxide (DLco) was measured using the single-breath technique (CHESTAC-65 V; Chest, Tokyo, Japan). Chest radiographs were obtained in all patients. ABG analyses were also performed. In cases associated with long-term domiciliary oxygen therapy, the arterial blood was obtained while breathing the predetermined oxygen therapy. Blood was collected to measure the levels of plasma brain natriuretic peptide (BNP) by a chemiluminescent enzyme immunoassay [14].

To assess dyspnea, the Japanese version of the Baseline Dyspnea Index (BDI) was used $[10,15,16]$, which has been previously validated. The BDI recognizes five grades for each of the following categories: functional impairment, magnitude of task and magnitude of effort, with higher scores indicating more severe dyspnea. The original Japanese version of the BDI/TDI was completed and the first two studies for validation were published in $1998[10,16]$. The newer Japanese version of the BDI/ TDI was subsequently developed and replaced the older version in 2008. However, the former Japanese version of the BDI was used in the present study.

\section{Statistical Analysis}

All results are expressed as means \pm SD. The relationship between two sets of data was analysed by both Spearman's rank correlation and by Pearson's correlation tests. Multiple regression analysis was performed to determine the association of the various variables with the BDI scores. The independent variables analysed were: age (years), smoking (pack-years), body mass index (BMI) $\left(\mathrm{kg} / \mathrm{m}^{2}\right), \mathrm{FEV}_{1}(\mathrm{~L}), \mathrm{IC} /$ predicted TLC, $\mathrm{DL}_{\mathrm{CO}}$ $(\mathrm{mL} / \mathrm{min} / \mathrm{mmHg}), \mathrm{PaO}_{2}(\mathrm{mmHg})$ and blood BNP levels $(\mathrm{pg} / \mathrm{mL})$. The $\mathrm{FEV}_{1}$ and IC/predicted TLC were selected as indices for airflow limitation and static hyperinflation, respectively. Multiple linear regressions were obtained by the standard, forward and backward stepwise methods. A p value of less than 0.05 was considered to be statistically significant.

\section{Results}

A total of 167 consecutive patients (147 males) were studied at the outpatient clinic between September 2007 
Table 1 Demographic details and correlations with the BDI score (Spearman's rank correlation test) in 167 subjects with stable COPD

\begin{tabular}{|c|c|c|c|c|c|c|c|}
\hline \multirow[t]{2}{*}{ variable } & \multirow[t]{2}{*}{ units } & \multirow[t]{2}{*}{ mean } & \multirow[t]{2}{*}{ SD } & \multirow[t]{2}{*}{$\max$} & \multirow[t]{2}{*}{$\min$} & \multicolumn{2}{|c|}{ Correlations with BDI score } \\
\hline & & & & & & Rs & $p$ value \\
\hline Age & years & 71.6 & 8.7 & 90 & 40 & -0.25 & 0.0014 \\
\hline BMl & $\mathrm{kg} / \mathrm{m}^{2}$ & 21.1 & 3.2 & 32.2 & 13.3 & 0.17 & 0.0320 \\
\hline Cumulative Smoking & pack-years & 71 & 42 & 268 & 4 & -0.23 & 0.0033 \\
\hline VC & Liters & 3.21 & 0.91 & 5.31 & 0.97 & 0.45 & $<0.0001$ \\
\hline VC & $\%$ pred & 102.6 & 22.8 & 156.2 & 38.6 & 0.48 & $<0.0001$ \\
\hline FVC & Liters & 3.05 & 0.89 & 5.25 & 0.99 & 0.47 & $<0.0001$ \\
\hline FVC & $\%$ pred & 97.4 & 22.5 & 147.9 & 40.9 & 0.51 & $<0.0001$ \\
\hline $\mathrm{FEV}_{1}$ & Liters & 1.52 & 0.72 & 3.46 & 0.39 & 0.60 & $<0.0001$ \\
\hline $\mathrm{FEV}_{1}$ & $\%$ pred & 68.5 & 27.4 & 133.0 & 13.0 & 0.60 & $<0.0001$ \\
\hline $\mathrm{FEV}_{1} / \mathrm{FVC}$ & $\%$ & 48.2 & 13.9 & 69.9 & 22.1 & 0.56 & $<0.0001$ \\
\hline TLC & Liters & 5.65 & 1.15 & 8.49 & 2.86 & 0.24 & 0.0022 \\
\hline TLC & $\%$ pred & 111.3 & 17.5 & 160.6 & 57.3 & 0.24 & 0.0022 \\
\hline IC & Liters & 2.09 & 0.68 & 3.57 & 0.69 & 0.45 & $<0.0001$ \\
\hline IC/TLC & $\%$ & 36.8 & 8.6 & 60.3 & 11.8 & 0.47 & $<0.0001$ \\
\hline IC/predicted TLC & $\%$ & 41.1 & 11.7 & 66.5 & 12.2 & 0.46 & $<0.0001$ \\
\hline DLco & $\mathrm{mL} / \mathrm{min} / \mathrm{mmHg}$ & 10.26 & 5.45 & 24.66 & 0.22 & 0.55 & $<0.0001$ \\
\hline DLco & $\%$ pred & 65.0 & 27.3 & 133.7 & 2.5 & 0.53 & $<0.0001$ \\
\hline $\mathrm{DLCO} / N_{\mathrm{A}}$ & $\mathrm{mL} / \mathrm{min} / \mathrm{mmHg} / \mathrm{L}$ & 2.35 & 1.16 & 6.52 & 0.03 & 0.52 & $<0.0001$ \\
\hline $\mathrm{PaO}_{2}$ & $\mathrm{mmHg}$ & 80.1 & 11.5 & 104.8 & 50.3 & 0.48 & $<0.0001$ \\
\hline $\mathrm{PaCO}_{2}$ & $\mathrm{mmHg}$ & 40.5 & 4.8 & 63.3 & 30.7 & 0.00 & 0.98 \\
\hline pH (arterial blood) & & 7.43 & 0.03 & 7.53 & 7.33 & 0.04 & 0.64 \\
\hline BNP & $\mathrm{pg} / \mathrm{mL}$ & 46.5 & 78.8 & 521.0 & 3.0 & -0.23 & 0.0033 \\
\hline BDI score & $(0-12)$ & 8.5 & 2.8 & 12 & 0 & - & - \\
\hline Gender & \multicolumn{7}{|c|}{147 Male/20 Female } \\
\hline Smoking Status & \multicolumn{7}{|c|}{29 Current/138 Former } \\
\hline
\end{tabular}

and September 2008. Their demographic details as well as pulmonary function test data are shown in Table 1. The average age and $\mathrm{FEV}_{1}$ were $71.6 \pm 8.7$ years and $1.52 \pm 0.72 \mathrm{~L}$, since the patient group included cases with mild to severe airflow limitation. All patients except for two were treated with inhaled bronchodilators plus high doses of inhaled corticosteroids. Six subjects were also given oral corticosteroids. Eight patients were treated with long-term oxygen therapy. Three subjects were managed with non-invasive positive pressure ventilation at home. The frequency distribution histograms of the BDI scores in the present study are shown in Figure 1. The scores are skewed towards the very mild end of the scale.

Table 1 shows the correlations between the BDI and 22 characteristics, and statistically significant correlations were observed between the BDI scores and 20 characteristics excluding the $\mathrm{PaCO}_{2}$. There was no correlation between the acid-base balance and the BDI scores. Table 2 shows simple correlations between three airflow limitation characteristics and the BDI scores, as well as between three static hyperinflation characteristics and the BDI scores. The Spearman rank correlation coefficients between the BDI score and the $\mathrm{FEV}_{1}$ (L), $\mathrm{FEV}_{1}$ (\%pred) and $\mathrm{FEV}_{1} / \mathrm{FVC}$ were $0.60,0.56$ and 0.56 , respectively. On the other hand, the BDI score was also correlated with the IC, IC/predicted

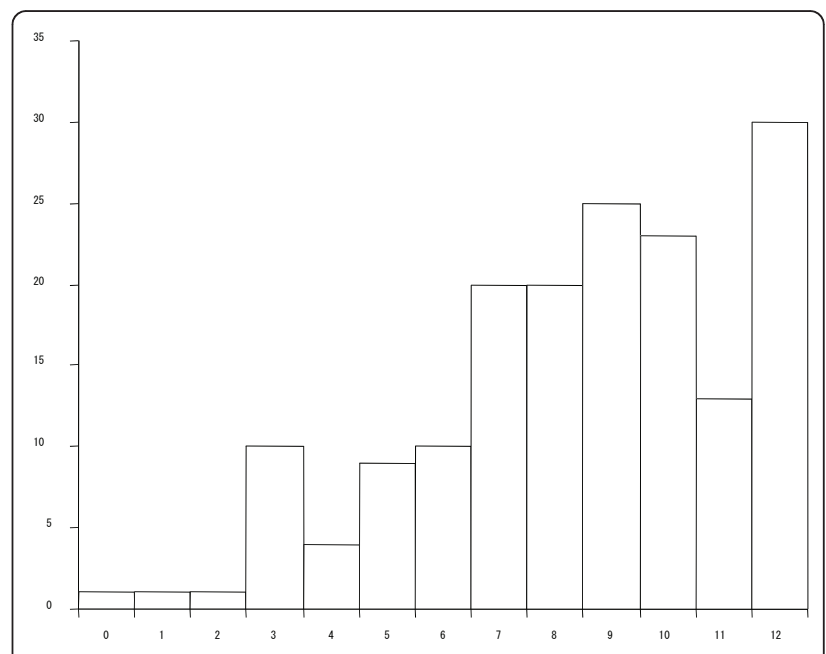

Figure 1 Frequency distribution histograms of the BDI scores. Lower scores indicate more severe dyspnea. 
Table 2 Correlations of the BDI score with airflow limitation and static hyperinflation

\begin{tabular}{|c|c|c|c|c|}
\hline & \multicolumn{2}{|c|}{ Spearman's rank correlation coefficients } & \multicolumn{2}{|c|}{ Pearson's correlation coefficient } \\
\hline & Rs & $\mathrm{p}$ value & $\mathbf{R}$ & $p$ value \\
\hline \multicolumn{5}{|l|}{ Dyspnea vs. Airflow limitation } \\
\hline BDI score vs. FEV 1 (L) & 0.60 & $<0.0001$ & 0.60 & $<0.0001$ \\
\hline BDI score vs. FEV 1 (\%pred) & 0.56 & $<0.0001$ & 0.57 & $<0.0001$ \\
\hline $\mathrm{BDI}$ score vs. FEV $1 / \mathrm{FVC}$ & 0.56 & $<0.0001$ & 0.57 & $<0.0001$ \\
\hline \multicolumn{5}{|l|}{ Dyspnea vs. Static Hyperinflation } \\
\hline BDI score vs. IC (L) & 0.45 & $<0.0001$ & 0.48 & $<0.0001$ \\
\hline BDI score vs. IC/predicted TLC & 0.46 & $<0.0001$ & 0.51 & $<0.0001$ \\
\hline BDI score vs. IC/TLC & 0.47 & $<0.0001$ & 0.48 & $<0.0001$ \\
\hline
\end{tabular}

TLC and IC/TLC ( $R s=0.45,0.46$ and 0.47 , respectively). Although all of the relationships studied were strongly correlated, the correlation coefficients were better between dyspnea and airflow limitation than between dyspnea and static hyperinflation. These results were similar when the Pearson's correlation coefficient was used instead (Table 2).

Stepwise multiple regression analyses were performed to identify those variables that could best predict the dyspnea assessed by the BDI score. The FEV 1 (L) and IC/predicted TLC, the airflow limitation and static hyperinflation characteristics with the strongest simple correlations with dyspnea in Table 2, as well as six other independent variables from Table 1 were included. We found out that the airflow limitation $\left(\mathrm{FEV}_{1}\right)$ and diffusion capacity for carbon monoxide (DLco) significantly accounted for $26.2 \%$ and $14.4 \%$ of the variance, respectively (Table 3 ). Since the cumulative $R^{2}$ was 0.406 , unknown factors still contribute to the BDI score. However, static hyperinflation was not a significant factor for clinical dyspnea using stepwise multiple regression analysis. The results were the same when we analyzed the 101 subjects with moderate to very severe COPD (excluding mild COPD) (data not shown).

Table 3 Results of stepwise multiple regression analyses to identify those variables that best predicted dyspnea assessed by the BDI score

\begin{tabular}{lc}
\hline & BDI score \\
\hline Independent variables & - \\
Age (years) & - \\
Smoking (pack-years) & - \\
$\mathrm{BMI}\left(\mathrm{kg} / \mathrm{m}^{2}\right)$ & 0.262 \\
$\mathrm{FEV} /(\mathrm{L})$ & - \\
$\mathrm{IC} / \mathrm{predicted} \mathrm{TLC}$ & 0.144 \\
$\mathrm{DL} \mathrm{CO}(\mathrm{mL} / \mathrm{min} / \mathrm{mmHg})$ & - \\
$\mathrm{PaO}_{2}(\mathrm{mmHg})$ & - \\
$\mathrm{BNP}(\mathrm{pg} / \mathrm{mL})$ & 0.406 \\
Cumulative $\mathrm{R}^{2}$ & \\
\hline
\end{tabular}

\section{Discussion}

The reason why patients with COPD feel subjective dyspnea is a simple question. However, answering this question is not simple, and clinicians need to understand the mechanisms responsible for dyspnea. It is widely accepted that the major limitation to exercise performance and the perception of breathlessness in COPD can be attributed to dynamic hyperinflation, although activity limitation and dyspnea in COPD is multifactorial. This has been explained by the following mechanism [1-3]. In COPD, the end-expiratory lung volume (EELV) is elevated as compared to healthy controls. During spontaneous breathing at rest in patients with expiratory flow limitations, the EELV is maintained at a level above the statically determined relaxation volume of the respiratory system. In flow-limited patients, the mechanical time-constant for lung emptying is increased in many alveolar units, but the expiratory time available during quiet breathing is often insufficient to allow the EELV to completely decline to its normal relaxation volume, and thus air trapping results. Dynamic hyperinflation occurs in flow-limited patients under the condition of increased ventilatory demand during exercise. Since the total lung capacity does not change during activity, the decrease in the IC must reflect an increase in the dynamic EELV, or the extent of dynamic hyperinflation. With the limitation of the tidal volume increase during exercise, dynamic hyperinflation results in restrictive mechanical constraints which, in the extreme, can lead to alveolar hypoventilation during exercise. In patients with COPD, breathing to higher lung volumes increases the total respiratory work, and thus potentiates the perception of breathlessness, which favors a decrease in physical activity.

The rate and magnitude of dynamic hyperinflation during exercise is generally measured in the laboratory setting by serial inspiratory capacity measurements. O'Donnell et al. reported that the exercise endurance time, Borg dyspnea ratings at the isotime near end-exercise, and IC are very reproducible indices [5], and that 
500 micrograms of nebulized ipratropium bromide can improve the exercise endurance time by $32 \%$ on average. This improvement correlated best with the IC improvement, but not with the FVC or $\mathrm{FEV}_{1}$ improvements, and the change in the Borg dyspnea ratings at the isotime near end-exercise also correlated well with the IC improvement [6]. An increased IC means reduced resting lung hyperinflation. Using a similar mechanism, the use of tiotropium bromide, salmeterol, or a fluticasone propionate/salmeterol combination was associated with sustained reductions in lung hyperinflation at rest and during exercise. The resultant increases in inspiratory capacity permitted a greater expansion of the tidal volume, and contributed to improvements in both exercise endurance and exertional dyspnea $[4,7,8]$.

In the present study, airflow limitation may have been a more important cause of clinical dyspnea than static hyperinflation. This clearly contradicts the above mentioned hypothesis, and the results of the laboratory exercise tests that are based upon it. Why is our result different? The first issue to consider is the different dyspnea evaluation methods used. We wanted to assess overall breathlessness during daily activities (clinical dyspnea) using the BDI score in the present study, whereas the Borg dyspnea ratings at isotime exercise has been used in most laboratory studies. Dyspnea during exercise using the Borg scale may provide a different type of information regarding dyspnea than clinical dyspnea [11]. Therefore, if the cause of COPD dyspnea is hypothesized to be dynamic hyperinflation, then it is necessary to evaluate clinical dyspnea instead of laboratory dyspnea.

Murariu et al. used a method similar to ours, and evaluated their maximal symptom-limited exercise on a cycle ergometer. Their correlation coefficients between the Wmax with the IC and FEV 1 were 0.81 and 0.54 , respectively, and a multiple regression model using the Wmax as the dependent variable revealed that the IC was the only significant contributor to the Wmax. They also reported that the $\mathrm{FEV}_{1}$ was not statistically significant [17]. Their study used the Wmax as the outcome, whereas we used clinical dyspnea instead. Although the methods of their analysis were similar, their comparison between airflow limitation and static hyperinflation resulted in completely different conclusions. Therefore, using clinical dyspnea as the outcome in our study probably explains the different results.

The main reason why dynamic hyperinflation can be hypothesized to be the main cause of dyspnea is the strong correlation between dynamic hyperinflation and dyspnea. Some researchers have argued against this hypothesis, since the presence of dynamic hyperinflation is not a universal finding during exercise [18]. We did not directly evaluate dynamic hyperinflation, but instead used the IC, which is the index for static hyperinflation. The IC may reflect dynamic hyperinflation inaccurately. Nevertheless, in the study conducted by O'Donnell et al., the correlation between the magnitude of the changes in the IC and Borg scores was strong, and they concluded that this explained why dynamic hyperinflation was causing dyspnea. However, correlations in cross-sectional studies and longitudinal studies do not necessarily match, and a statistical approach such as correlation coefficients may not resolve this issue. Airflow limitation causes dynamic hyperinflation, and hence airflow limitation, dynamic hyperinflation and dyspnea may be considered as the top of a pyramid, and it may not be necessary to consider them in a linear, causal relationship.

In the present study, airflow limitation explained only $26 \%$ of the BDI score, and airflow limitation plus the diffusing capacity explained an accumulative $41 \%$ of the BDI score. In the literature, it is thought that dyspnea measures are moderately correlated with pulmonary function, psychological function, and walking tests [19]. For example, a simple correlation between the BDI score and $\mathrm{FEV}_{1}$ has been reported to be statistically significant, with a correlation coefficient of 0.22-0.58 [10,19-21]. Although as per pulmonary function, the $\mathrm{FEV}_{1}$ and $\mathrm{FVC}$ are often evaluated for a correlation with clinical dyspnea, the correlations between the $\mathrm{FEV}_{1}$, static hyperinflation and clinical dyspnea have not been evaluated simultaneously. In addition, to our knowledge, this is the first study which proved that the diffusing capacity was a significant contributor to clinical dyspnea. This may indicate that emphysema-predominant subjects with COPD are conscious of stronger dyspnea. Our results obtained from the stepwise multiple regression analyses also indicate that there are other unmeasured factors that explain clinical dyspnea. Wijkstra et al. [22] reported that the transfer factor for carbon monoxide $\left(\mathrm{T}_{\mathrm{LCO}}\right)$ was strongly correlated with the six minute walking test and with the maximal work load, and that backward linear regression analysis selected the $\mathrm{T}_{\mathrm{LCO}}$ and peak esophageal pressure during a maximal semistatic maneuver as the most significant determinants for exercise performance. However, although they discussed the mechanism of correlation between the $\mathrm{T}_{\mathrm{LCO}}$ and exercise capacity, their causeeffect relationship is still unknown. Similarly, the mechanism of correlation between the diffusing capacity and clinical dyspnea is also unknown

There are also important considerations in the clinical practice setting. A common misunderstanding is that hypoxemia is causing dyspnea, and proper oxygen administration alone is enough. We want to emphasize that oxygen administration to alleviate dyspnea in COPD patients whose $\mathrm{PaO}_{2}$ is over $60 \mathrm{mmHg}$ is the wrong treatment. 
Since some researchers understand that COPD is a systemic disease, we should consider that other many factors possibly related to dyspnea. Since depression and anxiety are frequent in subjects with COPD, they have been investigated for their role in clinical dyspnea [19]. Unfortunately, a psychological assessment was not included in the present study.

We measured the BNP levels to investigate whether heart failure can play a role in dyspnea in COPD patients. It has been reported that BNP can be used to differentiate heart failure from respiratory diseases, including COPD, in patients with dyspnea [23]. Furthermore, COPD patients were reported to have higher levels of BNP as compared to controls [24]. Although the Spearman rank correlation test revealed a significant correlation between BNP levels and dyspnea, the stepwise multiple regression analysis did not. This does not explain what elevated BNP levels in subjects with COPD mean clinically, but the magnitude of this elevation may depend on the disease severity instead of dyspnea.

Some limitations of the present study should be mentioned. Most of the issues are related to the study design. First, this study is based just on correlation analysis, which is not the best way to detect the cause of a phenomenon. Second, although stepwise multiple regression analyses were performed to compare the relative contributions between airflow limitation and static hyperinflation on clinical dyspnea, over half of the contributory factors are still unknown. Third, we analyzed the $\mathrm{FEV}_{1}$ (L), $\mathrm{FEV}_{1}$ (\%pred) and $\mathrm{FEV}_{1} / \mathrm{FVC}$ as for airflow limitation. Although the $\mathrm{FEV}_{1}$ is very popular, it may be an older index of flow limitation. Other methods, including the tidal volume over the envelope in the flow-volume loop or the negative expiratory pressure during tidal breathing, should be compared against any measurements of clinical or laboratory dyspnea. The present study was also limited by the small number of participants and distinct male preponderance of the subjects. Although the latter is typically observed in subjects with COPD in Japan, generalization of these results to women with COPD may be uncertain.

\section{Conclusion}

Both static hyperinflation and airflow limitation contributed greatly to dyspnea in COPD patients. Our conclusion does not support the hypothesis that the perception of breathlessness in COPD is attributable to static hyperinflation. One possible reason for this inconsistent conclusion may be that different types of dyspnea (clinical dyspnea vs. laboratory dyspnea) have been assessed in previous investigations.

\section{Abbreviations}

COPD: chronic obstructive pulmonary disease; IC: inspiratory capacity; $\mathrm{FEV}_{1}$ : forced expiratory volume in 1 second; FVC: forced vital capacity; TLC: total lung capacity; BDI: Baseline Dyspnea Index; ABG: arterial blood gas; RV: residual volume; DLco: diffusion capacity for carbon monoxide; BNP: brain natriuretic peptide; BMI: body mass index; EELV: end-expiratory lung volume; TLCO: transfer factor for carbon monoxide

\section{Acknowledgements}

This study was partly funded by the NPO Medise in Japan.

\section{Author details}

'Department of Respiratory Medicine, Rakuwakai Otowa Hospital, Kyoto, Japan. ${ }^{2}$ Kyoto-Katsura Hospital, Kyoto, Japan. ${ }^{3}$ Department of Respiratory Care and Sleep Control Medicine, Graduate School of Medicine, Kyoto University, Kyoto, Japan.

\section{Authors' contributions}

KN was the physician responsible for all participants, developed the study design, and prepared the manuscript. MY and TN participated in the data collection and care for the participants. TO performed the statistical analysis. All authors read and approved the final manuscript.

\section{Competing interests}

KN has received lecture fees from Boehringer-Ingelheim and GlaxoSmithKline, but not in relation to the topic of the current manuscript. The other authors declare that they have no competing interests.

Received: 30 June 2011 Accepted: 11 October 2011

Published: 11 October 2011

\section{References}

1. O'Donnell $D E$, Laveneziana P: The clinical importance of dynamic lung hyperinflation in COPD. COPD 2006, 3(4):219-232.

2. O'Donnell $D E$, Laveneziana P: Dyspnea and activity limitation in COPD: mechanical factors. COPD 2007, 4(3):225-236.

3. O'Donnell DE, Webb KA: The major limitation to exercise performance in COPD is dynamic hyperinflation. J Appl Physiol 2008, 105(2):753-755, discussion 755-757.

4. O'Donnell DE, Fluge T, Gerken F, Hamilton A, Webb K, Aguilaniu B, Make B, Magnussen $\mathrm{H}$ : Effects of tiotropium on lung hyperinflation, dyspnoea and exercise tolerance in COPD. Eur Respir J 2004, 23(6):832-840.

5. O'Donnell DE, Lam M, Webb KA: Measurement of symptoms, lung hyperinflation, and endurance during exercise in chronic obstructive pulmonary disease. Am J Respir Crit Care Med 1998, 158(5 Pt 1):1557-1565.

6. O'Donnell DE, Lam M, Webb KA: Spirometric correlates of improvement in exercise performance after anticholinergic therapy in chronic obstructive pulmonary disease. Am J Respir Crit Care Med 1999, 160(2):542-549.

7. O'Donnell DE, Sciurba F, Celli B, Mahler DA, Webb KA, Kalberg CJ, Knobil K: Effect of fluticasone propionate/salmeterol on lung hyperinflation and exercise endurance in COPD. Chest 2006, 130(3):647-656.

8. O'Donnell DE, Voduc N, Fitzpatrick M, Webb KA: Effect of salmeterol on the ventilatory response to exercise in chronic obstructive pulmonary disease. Eur Respir J 2004, 24(1):86-94.

9. Casanova C, Cote C, de Torres JP, Aguirre-Jaime A, Marin JM, Pinto-Plata V, Celli BR: Inspiratory-to-total lung capacity ratio predicts mortality in patients with chronic obstructive pulmonary disease. Am J Respir Crit Care Med 2005, 171(6):591-597.

10. Hajiro T, Nishimura K, Tsukino M, Ikeda A, Koyama H, Izumi T: Analysis of clinical methods used to evaluate dyspnea in patients with chronic obstructive pulmonary disease. Am J Respir Crit Care Med 1998, 158(4):1185-1189.

11. Oga T, Nishimura K, Tsukino M, Hajiro T, Mishima M: Dyspnoea with activities of daily living versus peak dyspnoea during exercise in male patients with COPD. Respir Med 2006, 100(6):965-971.

12. Miller MR, Hankinson J, Brusasco V, Burgos F, Casaburi R, Coates A, Crapo R, Enright P, van der Grinten CP, Gustafsson P: Standardisation of spirometry. Eur Respir J 2005, 26(2):319-338. 
13. Diseases JSOC: The predicted values of pulmonary function testing and artrial blood gas in Japanese [in Japanese]. Jpn J Thorac Dis 2001, 39(5): appendix.

14. Cowie MR, Struthers AD, Wood DA, Coats AJ, Thompson SG, PooleWilson PA, Sutton GC: Value of natriuretic peptides in assessment of patients with possible new heart failure in primary care. Lancet 1997, 350(9088):1349-1353.

15. Mahler DA, Weinberg DH, Wells CK, Feinstein AR: The measurement of dyspnea. Contents, interobserver agreement, and physiologic correlates of two new clinical indexes. Chest 1984, 85(6):751-758.

16. Hajiro T, Nishimura K, Tsukino M, Ikeda A, Koyama H, Izumi T: Comparison of discriminative properties among disease-specific questionnaires for measuring health-related quality of life in patients with chronic obstructive pulmonary disease. Am J Respir Crit Care Med 1998, 157(3 Pt 1):785-790.

17. Murariu C, Ghezzo H, Milic-Emili J, Gautier H: Exercise limitation in obstructive lung disease. Chest 1998, 114(4):965-968.

18. Calverley PM: Dynamic hyperinflation: is it worth measuring? Proc Am Thorac Soc 2006, 3(3):239-244.

19. Eakin EG, Kaplan RM, Ries AL: Measurement of dyspnoea in chronic obstructive pulmonary disease. Qual Life Res 1993, 2(3):181-191.

20. Chhabra SK, Gupta AK, Khuma MZ: Evaluation of three scales of dyspnea in chronic obstructive pulmonary disease. Ann Thorac Med 2009, 4(3):128-132.

21. Ozalevli S, Ucan ES: The comparison of different dyspnoea scales in patients with COPD. J Eval Clin Pract 2006, 12(5):532-538.

22. Wijkstra PJ, TenVergert EM, van der Mark TW, Postma DS, Van Altena R, Kraan J, Koeter GH: Relation of lung function, maximal inspiratory pressure, dyspnoea, and quality of life with exercise capacity in patients with chronic obstructive pulmonary disease. Thorax 1994, 49(5):468-472.

23. Morrison LK, Harrison A, Krishnaswamy P, Kazanegra R, Clopton P, Maisel A: Utility of a rapid B-natriuretic peptide assay in differentiating congestive heart failure from lung disease in patients presenting with dyspnea. J Am Coll Cardiol 2002, 39(2):202-209.

24. Pesola GR: The use of B-type natriuretic peptide (BNP) to distinguish heart failure from lung disease in patients presenting with dyspnea to the emergency department. Acad Emerg Med 2003, 10(3):275-277.

doi:10.1186/1465-9921-12-135

Cite this article as: Nishimura et al:: Airflow limitation or static hyperinflation: which is more closely related to dyspnea with activities of daily living in patients with COPD? Respiratory Research 2011 12:135.

\section{Submit your next manuscript to BioMed Central and take full advantage of:}

- Convenient online submission

- Thorough peer review

- No space constraints or color figure charges

- Immediate publication on acceptance

- Inclusion in PubMed, CAS, Scopus and Google Scholar

- Research which is freely available for redistribution

Submit your manuscript at www.biomedcentral.com/submit
Biomed Central 